\title{
Dyspnoea and symptom burden in mild-moderate COPD: the Canadian Cohort Obstructive Lung Disease Study
}

\author{
Mathew Cherian (10) ${ }^{1}$, Dennis Jensen ${ }^{2,3,4}$, Wan C. Tan ${ }^{5}$, Sara Mursleen ${ }^{6}$, \\ Emma C. Goodall ${ }^{6}$, Gilbert A. Nadeau', Amnah M. Awan ${ }^{6}$, Darcy D. Marciniuk ${ }^{7}$ \\ Brandie L. Walker ${ }^{8}$, Shawn D. Aaron ${ }^{9}$, Denis E. O'Donnell (10 ${ }^{10}$, \\ Kenneth R. Chapman (i) ${ }^{11}$, François Maltais ${ }^{12}$, Paul Hernandez ${ }^{13}$, Don D. Sin ${ }^{5}$, \\ Andrea Benedetti ${ }^{14,15}$ and Jean Bourbeau (101,3
}

ABSTRACT Studies assessing dyspnoea and health-related quality of life (HRQoL) in chronic obstructive pulmonary disease (COPD) have focussed on patients in clinical settings, not the general population.

The aim of this analysis was to compare the prevalence and severity of dyspnoea and impaired HRQoL in individuals with and without COPD from the general population, focussing on mild-moderate COPD.

Analysis of the 3-year Canadian Cohort Obstructive Lung Disease (CanCOLD) study included four subgroups: mild COPD (Global Initiative for Chronic Obstructive Lung Disease (GOLD) 1); moderate COPD (GOLD 2); non-COPD smokers; and non-COPD never-smokers. The primary outcome was dyspnoea (Medical Research Council (MRC) scale), and the secondary outcome was HRQoL (COPD Assessment Test (CAT) score; Saint George's Respiratory Questionnaire (SGRQ) score). Subgroups were analysed by sex, physician-diagnosed COPD status and exacerbations.

1443 participants (mild COPD ( $n=397)$; moderate COPD $(n=262$ (; smokers $(n=449)$ and never-smokers $(\mathrm{n}=335)$ ) were studied. People with mild COPD were more likely to report more severe dyspnoea (MRC 2 versus 1) than those without COPD (OR (95\% CI) 1.42 (1.05-1.91)), and non-COPD never-smokers (OR (95\%CI) $1.64(1.07-2.52)$ ). Among people with mild COPD, more severe dyspnoea was reported in women versus men (MRC2 versus 1; OR (95\% CI) 3.70 (2.23-6.14)); people with, versus without, physician-diagnosed COPD (MRC2 versus 1; OR (95\% CI) 3.27 (1.71-6.23)), and people with versus without recent exacerbations (MRC2 versus $1 ; \geqslant 2$ versus 0 exacerbations: OR (95\% CI) 3.62 (1.02-12.86); $\mathrm{MRC} \geqslant 3$ versus $1 ; 1$ versus 0 exacerbation: OR (95\% CI): 9.24 (2.01-42.42)). Similar between-group differences were obtained for CAT and SGRQ scores.

Careful assessment of dyspnoea and HRQoL could help identify individuals for earlier diagnosis and treatment.

@ERSpublications

Individuals from a population-based study with mild COPD are more symptomatic than nonCOPD peers. Worse dyspnoea and quality of life was reported by people with mild COPD who are female, or have a physician diagnosis of COPD or recent exacerbations. https://bit.ly/2XE2B6S

Cite this article as: Cherian M, Jensen D, Tan WC, et al. Dyspnoea and symptom burden in mild-moderate COPD: the Canadian Cohort Obstructive Lung Disease Study. ERJ Open Res 2021; 7: 00960-2020 [https://doi.org/10.1183/23120541.00960-2020].

This article has supplementary material available from openres.ersjournals.com.

Data sharing statement: Individual participant data is owned by the CanCOLD investigators. GSK reviewed the analysis in an anonymized, aggregate form and does not own or have access to these data. Information on GSK's data sharing commitments can be found at www.clinicalstudydatarequest.com.

Received: 20 Dec 2020 | Accepted: 21 Dec 2020

( T) The authors 2021. This version is distributed under the terms of the Creative Commons Attribution Non-Commercial Licence 4.0. For commercial reproduction rights and permissions contact permissions@ersnet.org 


\section{Introduction}

Dyspnoea is a cardinal symptom of COPD, across all severities of airflow obstruction [1]. Over 70\% of people with diagnosed COPD seen in primary care experience dyspnoea, with $32 \%$ of people with mild airflow limitation (Global Initiative for Chronic Obstructive Lung Disease (GOLD) stage 1) experiencing moderate-to-severe dyspnoea (Medical Research Council (MRC) Scale $\geqslant 3$ ) $[1,2]$. Dyspnoea can precede COPD diagnosis, with people often misattributing this symptom to ageing, smoking, or deconditioning, thereby contributing to COPD under/late diagnosis [3-8].

Approximately half of Canadians with spirometrically defined COPD are estimated to have mild disease [9]; however, few studies have examined dyspnoea and health-related quality of life (HRQoL) in this prevalent group $[10,11]$. Therefore, our understanding of dyspnoea and impaired HRQoL on people with mild or undiagnosed COPD is limited. Addressing this knowledge gap is important because earlier diagnosis and treatment of COPD may reduce disease burden [12] and improve long-term health outcomes. In addition, dyspnoea relief is prioritised as an important patient-centred outcome and goal of COPD treatment $[7,13]$.

Facilitating earlier COPD diagnosis may be particularly important for women, who experience higher levels of dyspnoea, more frequent exacerbations and hospitalisations, and poorer HRQoL than men of a similar age and airflow obstruction $[14,15]$. Women are further disadvantaged by male-dominated bias in physician awareness, and the comparative lack of female representation in COPD clinical trials [16, 17]. Population-based studies in people with physician-diagnosed mild COPD have demonstrated that 23-34\% experienced exacerbations versus $12-19 \%$ in undiagnosed people [18]. Yet, most exacerbation studies focus on people with diagnosed, moderate-to-very-severe COPD [19-21]. Furthermore, people with and without a physician diagnosis of COPD require similar healthcare services access for exacerbation-like respiratory events [18].

The primary objective of this analysis of the Canadian Cohort Obstructive Lung Disease (CanCOLD) study population [22] was to compare the prevalence and severity of dyspnoea and impaired HRQoL among people with mild (GOLD1) and moderate (GOLD2) COPD with both ever- and never-smoking controls without COPD. Secondary objectives were to compare the prevalence and severity of dyspnoea and impaired HRQoL based on sex, physician-diagnosed COPD status, and recent history of exacerbations.

\section{Methods}

\section{Study design}

This analysis used data from the 3-year CanCOLD study: a longitudinal population-based cohort of randomly-sampled people from non-clinical settings in nine Canadian cities [18, 22]. The sampling strategy is elaborated in the Supplementary material.

CanCOLD comprised people with (post-bronchodilator forced expiratory volume in $1 \mathrm{~s}\left(\mathrm{FEV}_{1}\right) /$ forced vital capacity $(\mathrm{FVC})<0.70$ ) and without (post-bronchodilator $\mathrm{FEV}_{1} / \mathrm{FVC} \geqslant 0.70$ ) COPD and was subdivided into: mild COPD ( $\mathrm{FEV}_{1} \geqslant 80 \%$ predicted; GOLD1), moderate COPD $\left(50 \% \leqslant \mathrm{FEV}_{1}<80 \%\right.$ predicted; GOLD2), non-COPD current/former smokers ( $>20$ packs in a lifetime, or $>1$ cigarette day $^{-1}$ for $\geqslant 1$ year) and non-COPD never-smokers (figure 1). Socio-demographics, clinical status, spirometry, MRC dyspnoea ratings, COPD Assessment Test (CAT) scores, and Saint George's Respiratory Questionnaire (SGRQ) scores, were assessed at baseline (visit (V)1), 1.5 years (V2), and 3 years (V3). Exacerbation incidence was

Affiliations: 'Division of Respiratory Medicine, Dept of Medicine, McGill University Health Centre, Montreal, QC, Canada. ${ }^{2}$ Clinical Exercise and Respiratory Physiology Laboratory, Dept of Kinesiology and Physical Education, Faculty of Education, McGill University, Montréal, QC, Canada. ${ }^{3}$ Research Institute of the McGill University Health Centre, Translational Research in Respiratory Diseases Program and Respiratory Epidemiology and Clinical Research Unit, Montréal, QC, Canada. ${ }^{4}$ Research Centre for Physical Activity and Health, Faculty of Education, McGill University, Montréal, QC, Canada. ${ }^{5}$ Centre for Heart Lung Innovation, Dept of Medicine, University of British Columbia, Vancouver, BC, Canada. ${ }^{6} \mathrm{GSK}$, Mississauga, ON, Canada. ${ }^{7}$ Respiratory Research Centre, University of Saskatchewan, Saskatoon, SK, Canada. ${ }^{8}$ Division of Respirology, Dept of Medicine, University of Calgary, Calgary, AB, Canada. ${ }^{9}$ The Ottawa Hospital Research Institute, Ottawa, ON, Canada. ${ }^{10}$ Dept of Medicine/Physiology, Queens University, Kingston, ON, Canada. ${ }^{11}$ Asthma and Airway Centre, University Health Network and University of Toronto, Toronto, ON, Canada. ${ }^{12}$ Institut universitaire de cardiologie et de pneumologie de Québec, Université Laval, Québec, QC, Canada. ${ }^{13}$ Faculty of Medicine, Division of Respirology, Dalhousie University, Halifax, NS, Canada. ${ }^{14}$ Depts of Medicine and of Epidemiology, Biostatistics and Occupational Health, McGill University, Montreal, QC, Canada. ${ }^{15}$ Respiratory Epidemiology and Clinical Research Unit, McGill University, Montreal, QC, Canada.

Correspondence: Jean Bourbeau, Respiratory Epidemiology and Clinical Research Unit, Research Institute of the McGill University Health Centre, 5252 De Maisonneuve, room 3D.62, Montreal, QC, H4A 3S5, Canada. E-mail: jean.bourbeaudamcgill.ca 


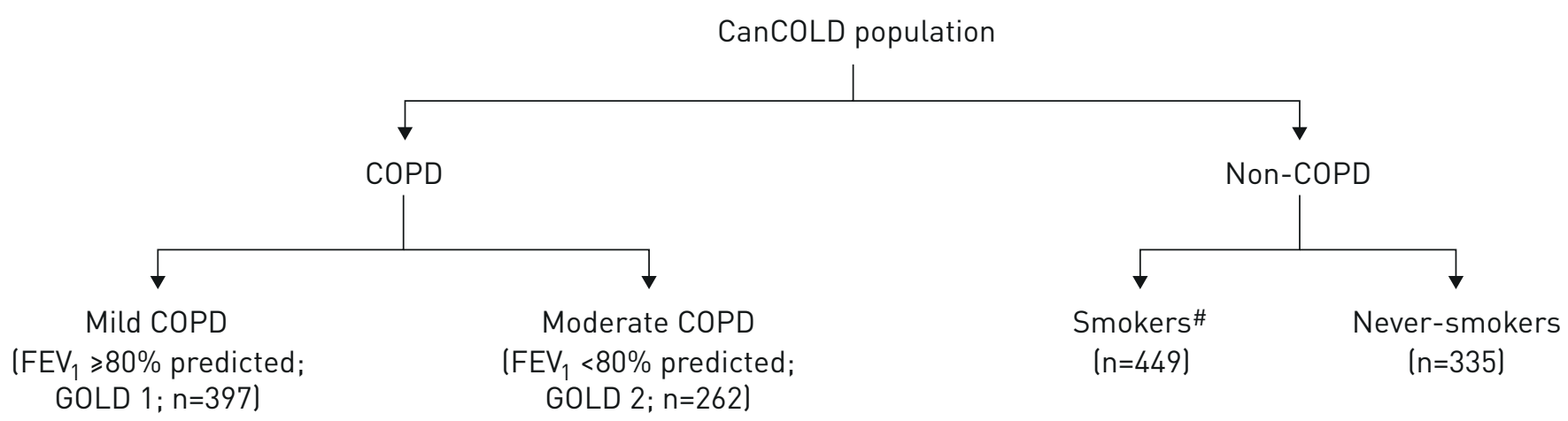

Subgroup analyses conducted for participants with COPD:

1. Women versus men

2. Physician-diagnosed COPD versus physician-undiagnosed COPD

3. People with and without a recent history of exacerbations

FIGURE 1 Study design and subgroups analysed. \#: Current or former smokers were defined as smoking >20 packs in a lifetime, or $>1$ cigarette.day ${ }^{-1}$ for $\geqslant 1$ year. Exacerbation history was limited to the 12 months before Visit 3 . The analysis of these data only included people for

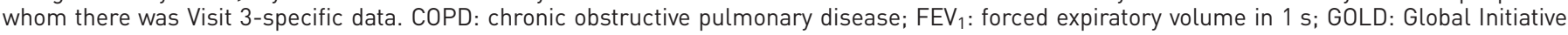
for Chronic Obstructive Lung Disease.

assessed every 3 months by telephone or online questionnaires. See the Supplement for key operational definitions. All participants provided written consent prior to enrolment in CanCOLD, and ethics and review board approval was obtained at all nine sites. The STROBE (STrengthening the Reporting of OBservational studies in Epidemiology) checklist [23] was used in the creation of this manuscript.

\section{Outcomes}

Dyspnoea was assessed using the MRC dyspnoea scale of 1-5 [24] because of its prognostic value [25] and use by the Canadian Thoracic Society [26]. HRQoL was assessed using the CAT and the SGRQ. The CAT was used for its clinical utility [26] and responsiveness [27], while the SGRQ was selected for its multidimensionality [28]. For more on outcome selection, see the Supplementary material. MRC, CAT and SGRQ scores from V1 were used for all analyses, except when analysing outcomes among people with different exacerbation frequencies where outcomes collected at V3 were used so as to have prior exacerbation history available. Exacerbation history, collected every 3 months, was limited to the 12 months before V3; the analysis of these data only included people with data available from V3.

\section{Statistical analysis}

For the primary objective, differences in the prevalence and severity of dyspnoea between people with COPD (mild and moderate) and those without COPD were compared using Chi-squared or Fisher's exact tests for categorical variables. Sensitivity analyses were conducted to 1) compare the mild COPD subgroup with the non-COPD group, and particularly with never-smokers; 2) excluding participants with a physician-diagnosis of asthma; and 3) excluding participants on respiratory medications. Multinomial logistic regression models were used to estimate adjusted odds ratios with 95\% confidence intervals for MRC 2 versus MRC 1 and MRC $\geqslant 3$ versus MRC 1, adjusting for relevant covariates (see the Supplementary material). Linear regression models were used to estimate adjusted $\beta$ with 95\% confidence intervals for CAT and SGRQ scores. For secondary objectives, differences were assessed using separate logistic regression models to compare outcomes between relevant groups, with results adjusted for the same covariates.

The study was powered for the primary analysis, comparing the odds of reporting MRC2 versus 1 between COPD ( $\mathrm{n}=659)$ and non-COPD $(\mathrm{n}=784)$ groups. With a proportion of MRC2 among the non-COPD group of 0.27 , the study had $>95 \%$ power to detect a proportion of MRC2 of $>0.37$ in the COPD group. The probability of a Type I error was 0.05 .

\section{Results}

Study population

The CanCOLD cohort assessed 1561 individuals at V1; 80 were excluded because MRC could not be assessed due to non-ambulatory functional status attributed to comorbidities other than COPD (see the 
TABLE 1 Demographics and baseline characteristics

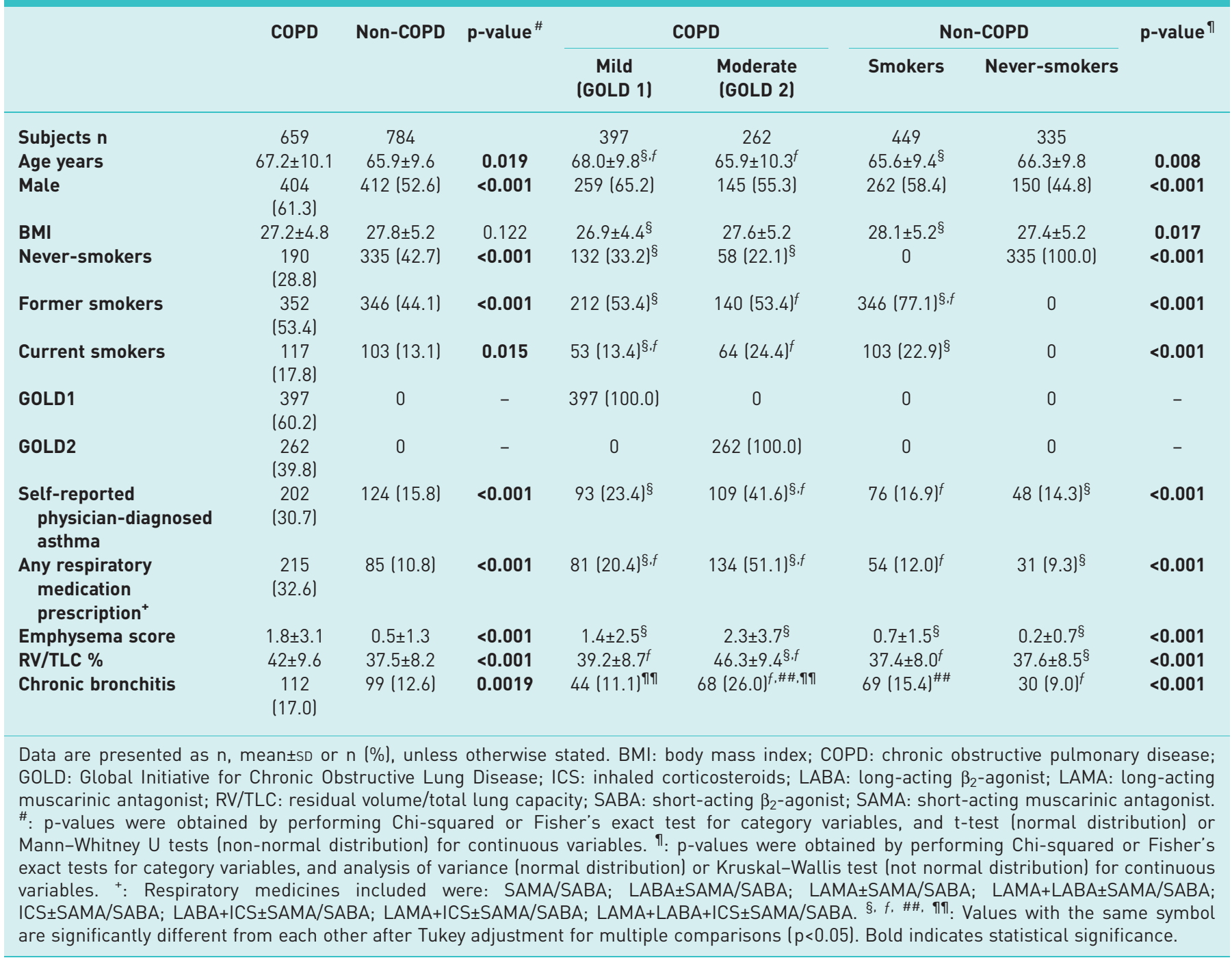

Supplementary material for details). An additional 38 people with GOLD3+ COPD were also excluded. Among the 1443 people included, 659 had COPD ( $n=397$ mild; $n=262$ moderate) and 784 did not have COPD ( $n=449$ smokers; $n=335$ never-smokers). People without COPD were generally younger, women and with a lesser smoking history compared with people with COPD. More people with versus without COPD self-reported having physician-diagnosed asthma (30.7\% versus $15.8 \%)$ and were prescribed respiratory medications (32.6\% versus $10.8 \%$ ) (table 1). Characteristics according to sex, physician-diagnosed COPD status and exacerbation frequency among people with COPD are shown in Table E4.

\section{Dyspnoea and HRQoL by COPD severity}

The prevalence of $\mathrm{MRC} \geqslant 2$ at baseline was greater in people with COPD (mild and moderate) versus people without COPD (smokers and never-smokers). MRC $\geqslant 3$ was reported more frequently in people with moderate COPD (12.2\%) than in people with mild COPD (3.5\%), and non-COPD smokers $(4.5 \%)$ and never-smokers (3.3\%) (figure 2a). Additionally, people with mild COPD were more likely to report MRC2 versus 1 than people without COPD (OR (95\% CI) 1.42 (1.05-1.91)), and particularly versus never-smokers (OR (95\% CI) 1.64 (1.07-2.52)) (figure 3). There were no statistically significant differences in reporting $\mathrm{MRC} \geqslant 3$ versus 1 between people with mild COPD and those without COPD. Similar results were obtained when participants with a physician-diagnosis of asthma or who reported use of respiratory medication(s) were excluded (tables E5 and E6). HRQoL was worse in people with COPD (mild and moderate) compared to people without COPD (higher CAT ( $\beta$ [95\%CI]: $1.06(0.48-1.64)$ ) and SGRQ scores $(\beta$ (95\% CI) 4.34 (2.84-5.84)) (figure 4). No differences in HRQoL were seen between people with mild COPD compared with people without COPD or never smokers. 

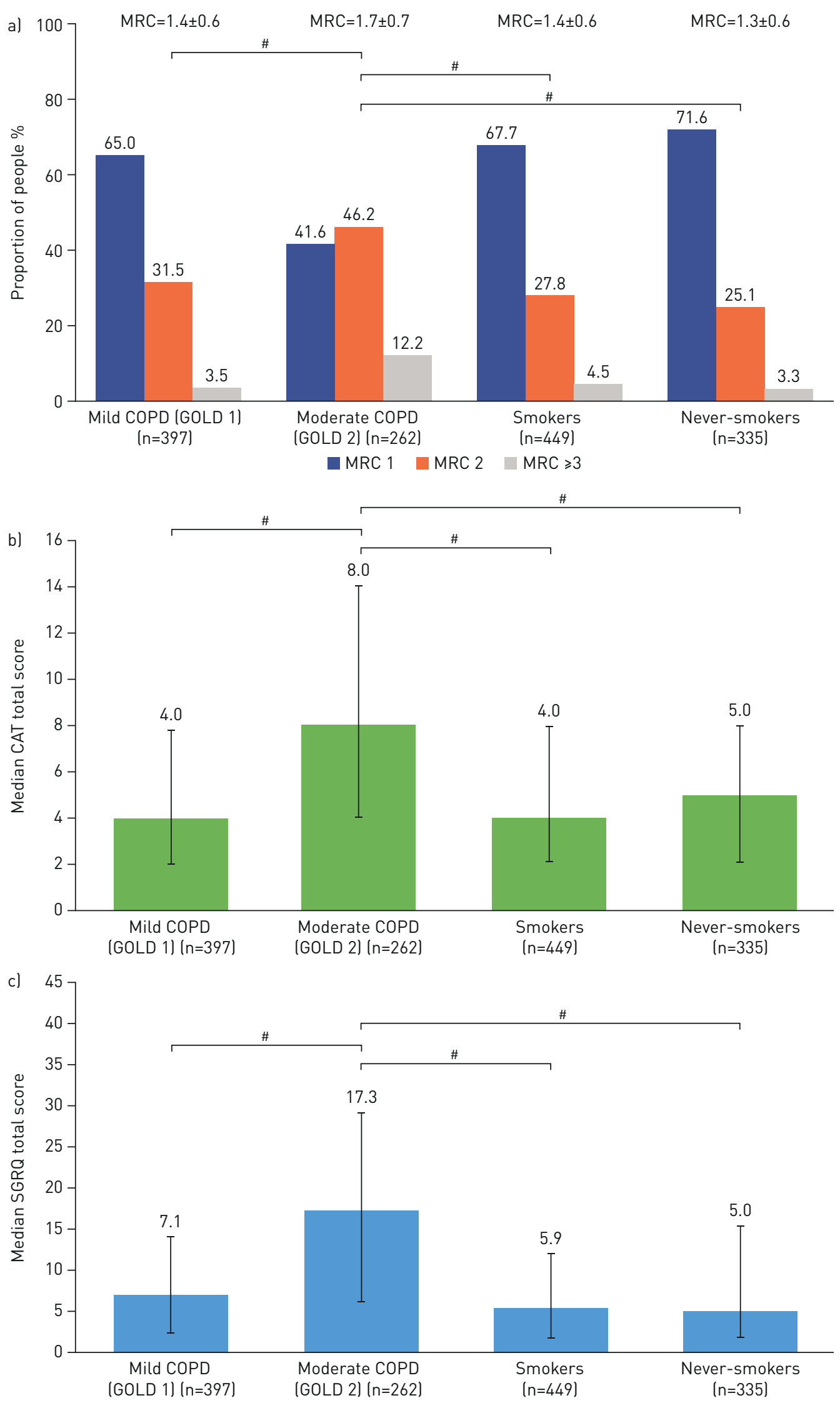
FIGURE 2 Prevalence and severity of dyspnoea (Medical Research Council (MRC)) (a), and health-related quality of life (COPD Assessment Test (CAT) total score (b); SGRQ total score (c) at baseline. Error bars represent quartiles 1 and 3. Values above the bars in panel (a) represent the mean \pm SD MRC dyspnoea scores for each group. CAT: COPD Assessment Test; COPD: chronic obstructive pulmonary disease; GOLD: Global Initiative for Chronic Obstructive Lung Disease; MRC: Medical Research Council; SGRQ: St George's Respiratory Questionnaire. \#: significantly different from each other after Tukey adjustment for multiple comparisons ( $p<0.05$ ).

\section{Dyspnoea and HRQoL by sex}

Within the COPD group, more women had $M R C \geqslant 2$ compared with men (figure $5 \mathrm{a}$ ). Women with COPD were more likely to report MRC2 versus 1 (OR (95\% CI) 3.12 (2.14-4.55)), and MRC $\geqslant 3$ versus 1 (OR (95\% CI) 4.50 (2.27-8.92)) (figure 3). Women with COPD also reported worse HRQoL, as evidenced by higher CAT ( $\beta(95 \%$ CI) 2.25 (1.33-3.18)) and SGRQ scores ( $\beta$ (95\% CI) 5.55 (3.43-7.66)) (figures 4, 6a and b). Similarly, among people with mild COPD, women had a higher mean baseline MRC (table 2) and were more likely to report MRC2 versus 1 (OR (95\% CI) 3.70 (2.23-6.14)) and MRC $\geqslant 3$ versus 1 (OR (95\% CI) 5.56 (1.74-17.79)) (figure 3). Women compared with men with mild COPD reported worse HRQoL (CAT; $\beta$ (95\% CI) 1.40 (0.39-2.40); SGRQ; $\beta$ (95\% CI) 3.88 (1.60-6.15) (figure 4, table 2).

\section{Dyspnoea and HRQoL by physician-diagnosed COPD}

Among people with COPD, those with versus without physician-diagnosed COPD reported greater dyspnoea severity (figure 5b). People with versus without a diagnosis were more likely to report MRC2 versus 1 (OR (95\% CI) 2.64 (1.71-4.08)), MRC $\geqslant 3$ versus 1 (OR (95\% CI) 5.01 (2.40-10.45)) (figure 3) and worse HRQoL (CAT; $\beta$ (95\% CI) 4.78 (3.76-5.80); SGRQ; $\beta$ (95\% CI) 10.08 (7.74-12.42)) (figures 4, 6c and d). Among the mild COPD subgroup, people with a diagnosis had a higher mean baseline MRC (table 2) and were more likely to report MRC2 versus 1 (OR (95\% CI) 3.27 (1.71-6.23)), and both a higher CAT score ( $\beta$ (95\% CI) 3.29 (2.01-4.57)) and higher SGRQ score ( $\beta$ (95\% CI) 7.23 (4.33-10.12)) (figures 3 and 4).

\section{Dyspnoea and HRQoL by exacerbation history}

Of the 659 people with COPD, V3 follow up data was available for 467 people at the time of analysis (see the Supplementary material). People with COPD who had exacerbations in the 12 months preceding V3 reported higher mean MRC at V3 than people who had not experienced an exacerbation (figure 5c). People who experienced $\geqslant 2$ exacerbations were more likely to report MRC2 versus 1 (OR (95\% CI) 2.49 $(1.12-5.56))$, MRC $\geqslant 3$ versus 1 (OR (95\% CI) 5.30 (1.41-19.92)) and worse HRQoL (CAT; $\beta$ (95\% CI) 2.79 (0.82-4.76); SGRQ; $\beta$ (95\% CI) $12.21(7.98-16.44)$ ) than people who had not experienced an exacerbation (figures 3 and 4). People who experienced one exacerbation in the preceding 12 months were more likely to report MRC $\geqslant 3$ versus 1 (OR (95\% CI) 4.76 (1.85-12.26)) and worse HRQoL (CAT; $\beta$ (95\% CI) 2.85 (1.39-4.32); SGRQ; $\beta$ (95\% CI): 8.55 (5.38-11.72)) than those with no exacerbations (figures 3 and 4 ).

Of the people with mild COPD, $19.5 \%$ experienced $\geqslant 1$ exacerbation in the previous 12 months. People with mild COPD who experienced $\geqslant 2$ exacerbations in the previous 12 months were more likely to report MRC2 versus 1 (OR (95\% CI) 3.62 (1.02-12.86)), MRC $\geqslant 3$ versus 1 (OR (95\% CI) 12.11 (1.30-112.93)), and higher SGRQ score ( $\beta$ (95\% CI) 10.61 (4.54-16.68)) than people who had not experienced an exacerbation. No statistically significant difference was seen in the CAT score between people with mild-COPD who reported $\geqslant 2$ exacerbations versus 0 exacerbations. People with mild COPD who experienced 1 exacerbation in the previous 12 months were more likely to report MRC $\geqslant 3$ versus 1 (OR (95\% CI) 9.24 (2.01-42.42)) and worse HRQoL (CAT; $\beta$ (95\% CI) 2.15 (0.23-4.06); SGRQ; $\beta$ (95\% CI) 6.67 (2.61-10.73)) than those with no exacerbations (figures 3 and 4 , table 2 ).

\section{Discussion}

CanCOLD is the first observational cohort study to compare dyspnoea and HRQoL in people with mild COPD versus people without COPD from a large non-clinical population. Interestingly, it reveals that individuals with mild COPD were more likely to report clinically significant dyspnoea (MRC2 versus 1) and worse HRQoL than those without COPD, particularly never-smokers, confirming that symptoms can be significant even in mild COPD. Among people with mild COPD, more severe dyspnoea and worse HRQoL were reported by women, people with physician-diagnosed COPD, and people with recent exacerbation(s). These findings were independent of age, body mass index, smoking history, respiratory medication use and comorbidities, including asthma. These results are unique and extend our knowledge on the prevalence and severity of dyspnoea and impaired HRQoL beyond patients with moderate-to-very severe COPD recruited from clinical settings to people with mild COPD recruited from the general-population. 
a)

Overall $(n=1443)$

COPD ( $n=659)$ versus non-COPD ( $n=784)$

Mild COPD ( $\mathrm{n}=397$ ) versus non-COPD ( $\mathrm{n}=784)$

Mild COPD ( $\mathrm{n}=397$ ) versus never-smokers ( $\mathrm{n}=335$ )

Mild COPD ( $\mathrm{n}=397$ ) versus smokers ( $\mathrm{n}=449$ )

Smokers ( $\mathrm{n}=449$ ) versus never-smokers ( $\mathrm{n}=335$ )

$\overline{\mathrm{COPD}}(\mathrm{n}=6 \overline{59}) \overline{ }$

Women $(\mathrm{n}=255)$ versus men $(\mathrm{n}=404)$

Diagnosed ( $n=163)$ versus undiagnosed $(n=496)$

1 exacerbation ( $n=74$ ) versus 0 exacerbation $(n=355)$

$\geqslant 2$ exacerbations $(n=38)$ versus 0 exacerbation $(n=355)$

Mild COPD (GOLD 1) ( $\mathrm{n}=397)$ \#

Women $(n=138)$ versus men $(n=259)$

Diagnosed $(n=66)$ versus undiagnosed $(n=331)$

1 exacerbation $(n=39)$ versus 0 exacerbation $(n=227)$

$\geqslant 2$ exacerbations $(n=16)$ versus 0 exacerbation $(n=227)$

Moderate COPD (GOLD 2) (n=262)\#

Women ( $n=117)$ versus men $(n=145)$

Diagnosed $(n=97)$ versus undiagnosed $(n=165)$

1 exacerbation ( $n=35$ ) versus 0 exacerbation $(n=128)$

$\geqslant 2$ exacerbations ( $n=22$ ) versus 0 exacerbation $(n=128)$

b)

Overall ( $n=1443)$

COPD $(n=659)$ versus non-COPD $(n=784)$

Mild COPD ( $n=397)$ versus non-COPD $(n=784)$

Mild COPD ( $\mathrm{n}=397$ ) versus never-smokers ( $\mathrm{n}=335$ )

Mild COPD ( $n=397)$ versus smokers ( $n=449$ )

Smokers ( $n=449$ ) versus never-smokers ( $n=335$ )

COPD $(\mathrm{n}=65 \overline{9}) \overline{ }$

Women $(\mathrm{n}=255)$ versus men $(\mathrm{n}=404)$

Diagnosed $(n=163)$ versus undiagnosed $(n=496)$

1 exacerbation ( $n=74)$ versus 0 exacerbation $(n=355)$

$\geqslant 2$ exacerbations $(n=38)$ versus 0 exacerbation $(n=355)$

Mild COPD (GOLD 1) ( $\mathrm{n}=397)^{\#}$

Women $(n=138)$ versus men $(n=259)$

Diagnosed $(n=66)$ versus undiagnosed $(n=331)$

1 exacerbation ( $n=39$ ) versus 0 exacerbation $(n=227)$

$2.28(1.26-4.12)$

$1.93(1.04-3.55)$

$1.82(0.74-4.47)$

$1.91(0.67-5.49)$

3.12 (2.14-4.55)

2.64 (1.71-4.08)

$1.23(0.65-2.30)$

$2.49(1.12-5.56)$

$3.70(2.23-6.14)$

$3.27(1.71-6.23)$

$0.81(0.31-2.11)$

$3.62(1.02-12.86)$
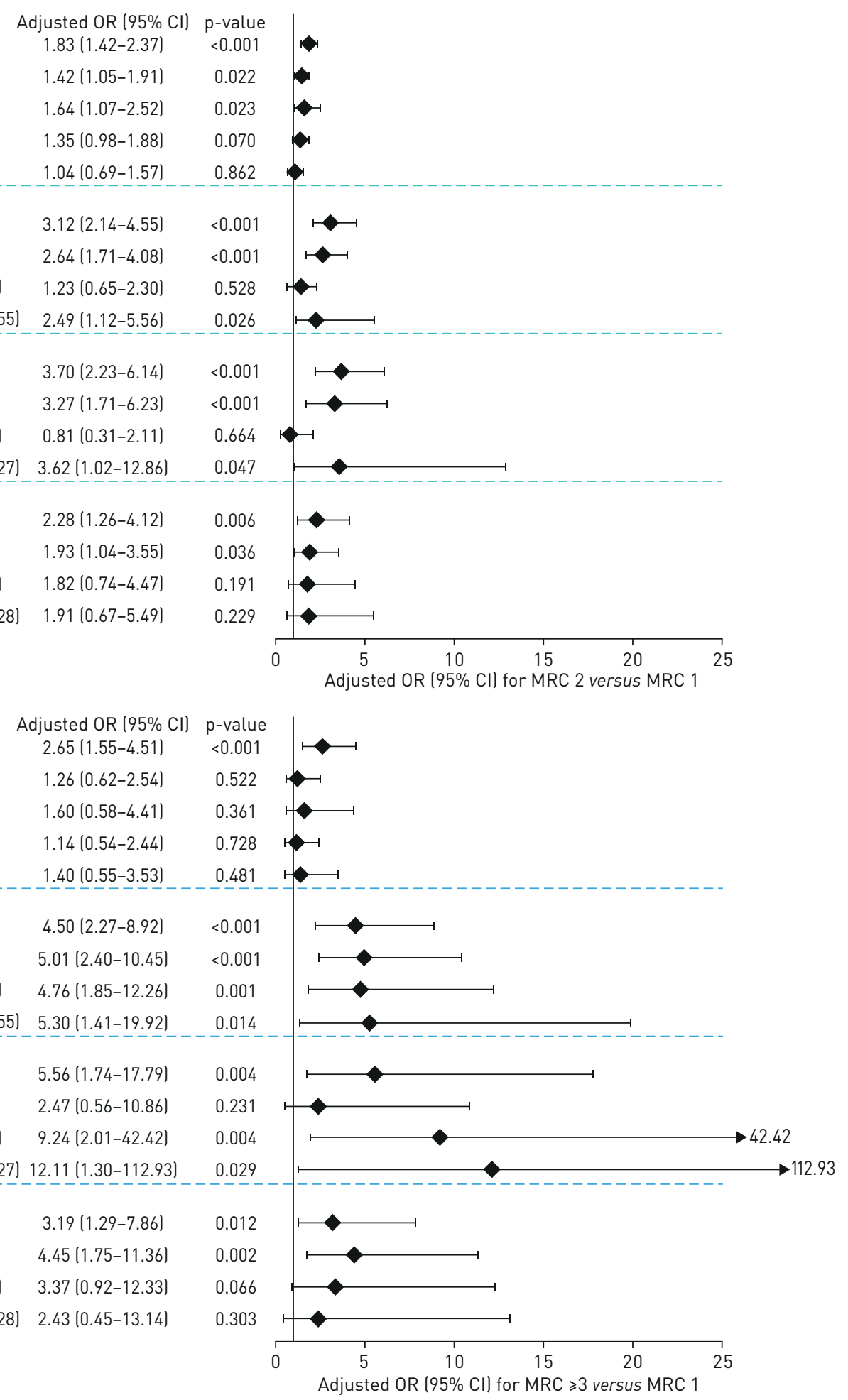

FIGURE 3 Odds ratios of dyspnoea severity for: a) MRC 2 versus MRC 1 and b) MRC $\geqslant 3$ versus MRC 1. MRC was measured at baseline for comparisons by sex and physician diagnosis of COPD, and at Visit 3 for comparisons by exacerbation history. \#: For analysis by exacerbation status, $n$ were as follows: COPD: $n=467$; mild-COPD (GOLD 1): $n=282$; moderate-COPD (GOLD 2): $n=185$. Adjusted OR were obtained by performing multivariate multinomial logistic regression models, adjusted for sex, age, BMI, smoking history, cardiovascular comorbidities, and other respiratory comorbidities. For women versus men comparisons, sex was not included as a covariate. For smokers versus never-smokers, smoking history was not included as a covariate. To estimate the association between exacerbations and MRC, exacerbations were observed in preceding 12 months at Visit 3. BMI: body mass index; COPD: chronic obstructive pulmonary disease; GOLD: Global Initiative for Chronic Obstructive Lung Disease; MRC: Medical Research Council. 
a)

Overall ( $n=1443$ )

COPD ( $n=659)$ versus non-COPD $(n=784)$

Mild COPD ( $\mathrm{n}=397$ ) versus non-COPD ( $\mathrm{n}=784$ )

Mild COPD ( $\mathrm{n}=397$ ) versus never-smokers ( $\mathrm{n}=335$ )

Mild COPD ( $n=397$ ) versus smokers ( $n=449$ )

Smokers ( $\mathrm{n}=449$ ) versus never-smokers ( $\mathrm{n}=335$ )

$\operatorname{COPD}(n=659) \#$

Women $(n=255)$ versus men $(n=404)$

Diagnosed ( $n=163$ ) versus undiagnosed $(n=496)$

1 exacerbation ( $n=74$ ) versus 0 exacerbation ( $n=355$ )

$\geqslant 2$ exacerbations ( $n=38$ ) versus 0 exacerbation $(n=355$ )

Mild COPD (GOLD 1) (n=397)\#

Women $(n=138)$ versus men $(n=259)$

Diagnosed $(n=66)$ versus undiagnosed $(n=331)$

1 exacerbation $(n=39)$ versus 0 exacerbation $(n=227)$

$\geqslant 2$ exacerbations $(n=16)$ versus 0 exacerbation $(n=227)$

Moderate COPD (GOLD 2) $(n=262)^{\#}$

Women ( $\mathrm{n}=117)$ versus men $(\mathrm{n}=145)$

Diagnosed ( $n=97)$ versus undiagnosed $(n=165)$

1 exacerbation $(n=35)$ versus 0 exacerbation $(n=128)$

$\geqslant 2$ exacerbations $(n=22)$ versus 0 exacerbation $(n=128) 2.50(-0.33-5.33)$

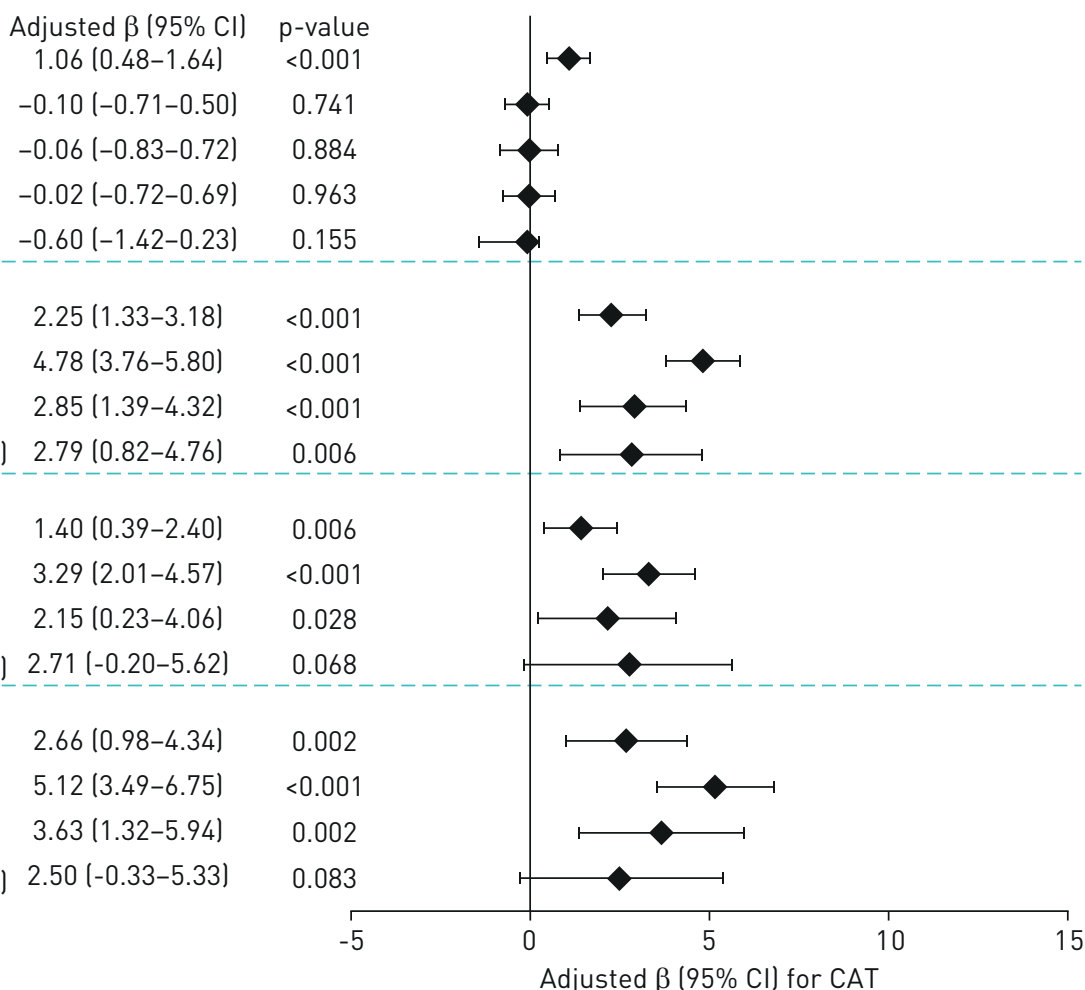

b)

Overall ( $n=1443$ )

COPD ( $n=659)$ versus non-COPD ( $n=784)$

Mild COPD ( $\mathrm{n}=397$ ) versus non-COPD ( $\mathrm{n}=784$ )

Mild COPD ( $\mathrm{n}=397$ ) versus never-smokers ( $\mathrm{n}=335$ )

Mild COPD ( $n=397$ ) versus smokers ( $n=449$ )

Smokers ( $\mathrm{n}=449$ ) versus never-smokers $(\mathrm{n}=335)$

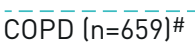

Women $(\mathrm{n}=255)$ versus men $(\mathrm{n}=404)$

Diagnosed ( $n=163$ ) versus undiagnosed ( $n=496)$

1 exacerbation $(n=74)$ versus 0 exacerbation $(n=355)$

Adjusted $\beta^{*}(95 \% \mathrm{Cl}) \quad \mathrm{p}$-value

$4.34(2.84-5.84) \quad<0.001$

$1.06(-0.44-2.57) \quad 0.166$

$1.09(-1.80-3.99) \quad 0.459$

$1.13(-0.44-2.71) \quad 0.158$

$-0.77(-3.76-2.22)$

$5.55(3.43-7.66)$

$10.08(7.74-12.42)$

$8.55(5.38-11.72)$

$\geqslant 2$ exacerbations $(n=38)$ versus 0 exacerbation $(n=355) 12.21 \quad(7.98-16.44)$ Mild COPD (GOLD 1) (n=397) \#

Women $(n=138)$ versus men $(n=259)$

Diagnosed $(n=66)$ versus undiagnosed $(n=331)$

1 exacerbation $(n=39)$ versus 0 exacerbation $(n=227)$

$3.88(1.60-6.15)$

$7.23(4.33-10.12)$

$6.67(2.61-10.73)$

$\geqslant 2$ exacerbations $(n=16)$ versus 0 exacerbation $(n=227) 10.61(4.54-16.68)$

Moderate COPD (GOLD 2) (n=262) \#

Women ( $\mathrm{n}=117)$ versus men $(\mathrm{n}=145)$

Diagnosed ( $n=97)$ versus undiagnosed $(n=165)$

$2.55(0.90-7.21)$

$3.99(1.28-12.48)$

1 exacerbation $(n=35)$ versus 0 exacerbation $(n=128)$

$2.97(0.66-13.32)$

$\geqslant 2$ exacerbations $(n=22)$ versus 0 exacerbation $(n=128) 2.24(0.35-14.26)$ $-\underline{0.613}$

$<0.001$

$<0.001$

$<0.001$

$<0.001$

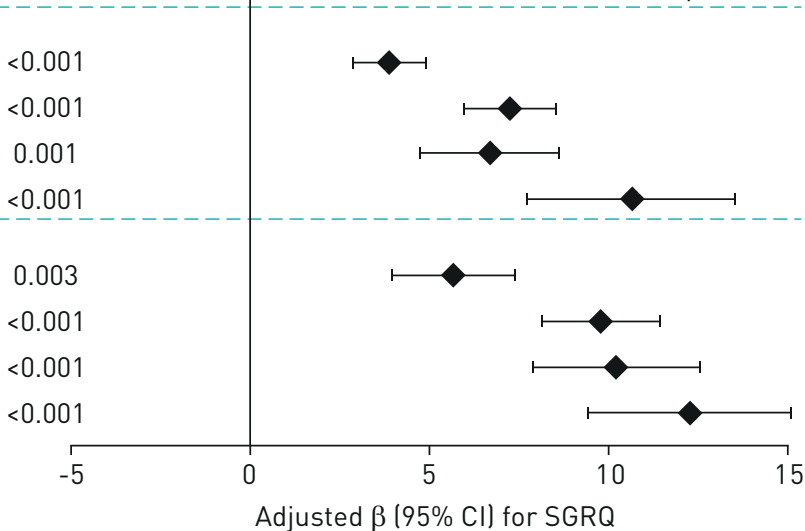

FIGURE 4 Adjusted $\beta$ of health-related quality of life for: a) CAT and b) SGRQ. CAT and SGRQ were measured at baseline for comparisons by sex and physician diagnosis of COPD, and at Visit 3 for comparisons by exacerbation history. ${ }^{\text {: }}$. For analysis by exacerbation status, $\mathrm{n}$ were as follows: COPD: $n=467$; mild-COPD (GOLD 1): $n=282$; moderate-COPD (GOLD 2): $n=185$. Adjusted $\beta$ were obtained by performing multivariate linear regression models, adjusted for sex, age, BMI, smoking history, cardiovascular comorbidities and other respiratory comorbidities. For women versus men comparisons, sex was not included as a covariate. For smokers versus never-smokers, smoking history was not included as a covariate. To estimate the association between exacerbations and CAT or SGRQ, exacerbations were observed in preceding 12 months at Visit 3. BMI: body mass index; CAT: COPD Assessment Test; COPD: chronic obstructive pulmonary disease; GOLD: Global Initiative for Chronic Obstructive Lung Disease; SGRQ: St George's Respiratory Questionnaire. 

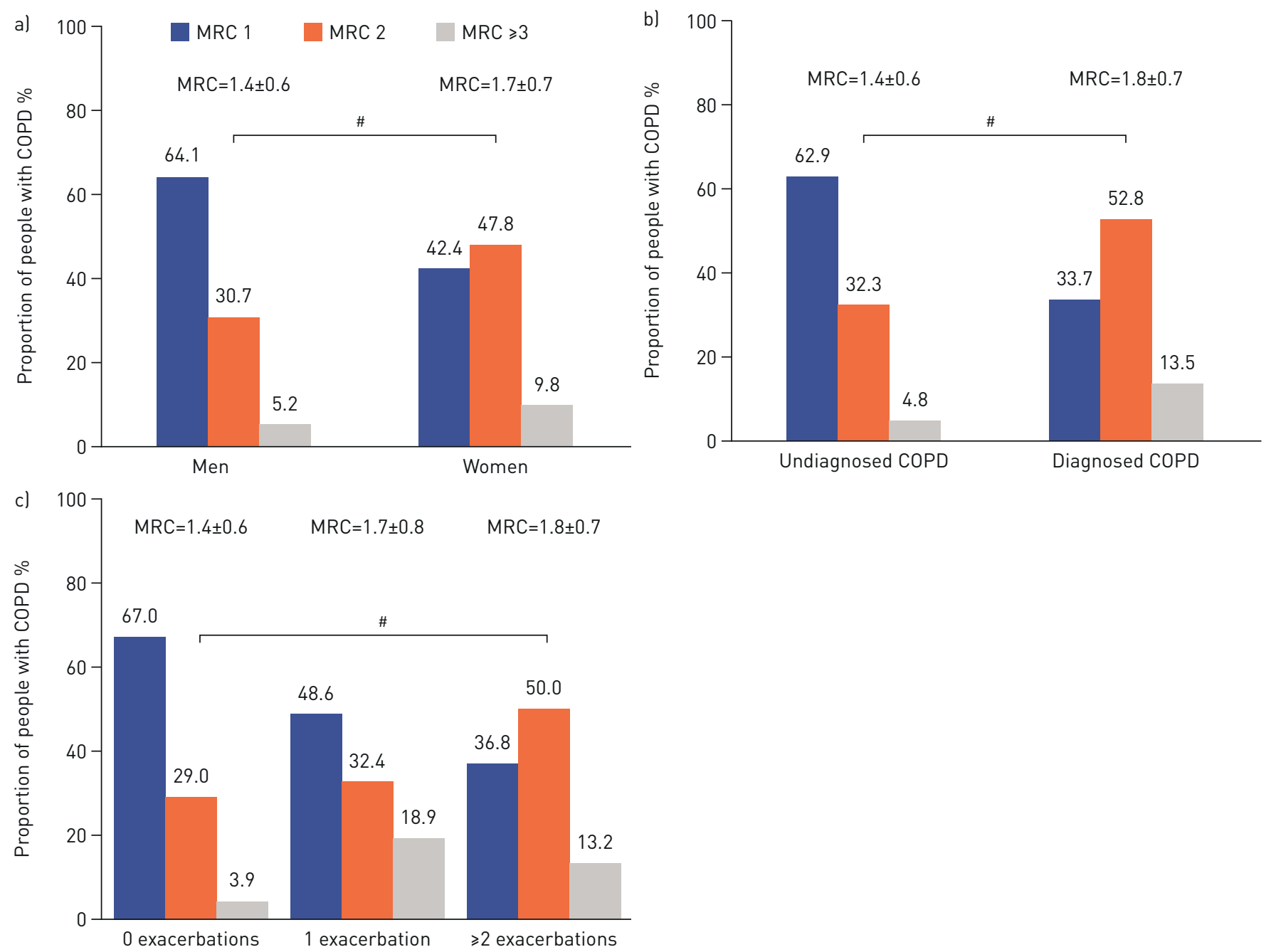

FIGURE 5 Dyspnoea severity for people with COPD by: a) sex, b) the presence of a physician diagnosis of COPD, and c) exacerbation frequency. MRC was measured at baseline for comparisons by sex and physician diagnosis of COPD, and at Visit 3 for comparisons by exacerbation history. Values above the bars represent the mean \pm SD MRC dyspnoea scores for each group. \# : Significantly different ( $p<0.001)$. $p$-values were obtained by performing Chi-squared or Fisher's exact test for category variables. For continuous variables, $p$-values were obtained by t-test (normal distribution) or Mann-Whitney U-test (not normal distribution) for sex and physician diagnosis subgroups. ANOVA (normal distribution) or Kruskal-Wallis test (not normal distribution) were performed for exacerbation subgroups. Analysis of variance subgroup comparisons of mean \pm SD differences by sex, presence of a physician diagnosis of COPD, and exacerbation frequency were all significant (p<0.001). COPD: chronic obstructive pulmonary disease; MRC: Medical Research Council.

Few studies have focussed solely on mild COPD $[1,10]$. A large observational study using general-practitioner data reported that of 7359 people with GOLD1 COPD, 28.0\% had MRC1, 40.5\% had MRC2 and $31.5 \%$ had MRC $\geqslant 3$ [1]. Furthermore, in a study across 56 primary-care and specialty centres, $>50 \%$ of people with GOLD1 COPD reported dyspnoea of modified MRC (mMRC) $\geqslant 2$ (equivalent to $\mathrm{MRC} \geqslant 3)$ [10]. In contrast, people with GOLD1 COPD in our study reported predominantly MRC1 (65.0\%), with $31.5 \%$ and $3.5 \%$ reporting MRC2 and $\mathrm{MRC} \geqslant 3$, respectively. Also, a study of people with GOLD2 COPD recruited from outpatient-clinics reported a mean mMRC of 1.3 (equivalent to mean MRC of 2.3) [29]. By comparison, people with GOLD2 in our study reported a slightly lower mean MRC of 1.7. These variations in dyspnoea severity may be because earlier studies recruited from clinical settings and included participants with physician-diagnosed COPD. Neither did they include direct comparisons to controls without COPD. Conversely, our cohort was a random sample from the general-population and included people with COPD confirmed by post-bronchodilator spirometry, and many who never received a physician-diagnosis [1, 10]. Accordingly, we observed that people reporting a physician-diagnosis of COPD prior to their participation in CanCOLD had more dyspnoea and worse HRQoL than people with COPD without a prior physician-diagnosis. Our study is unique in that it demonstrates that dyspnoea can be clinically relevant even in people with mild COPD, and that HRQoL is worse among people with mild-moderate COPD, recruited from the general population. However, when comparing individuals with 


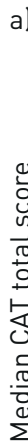
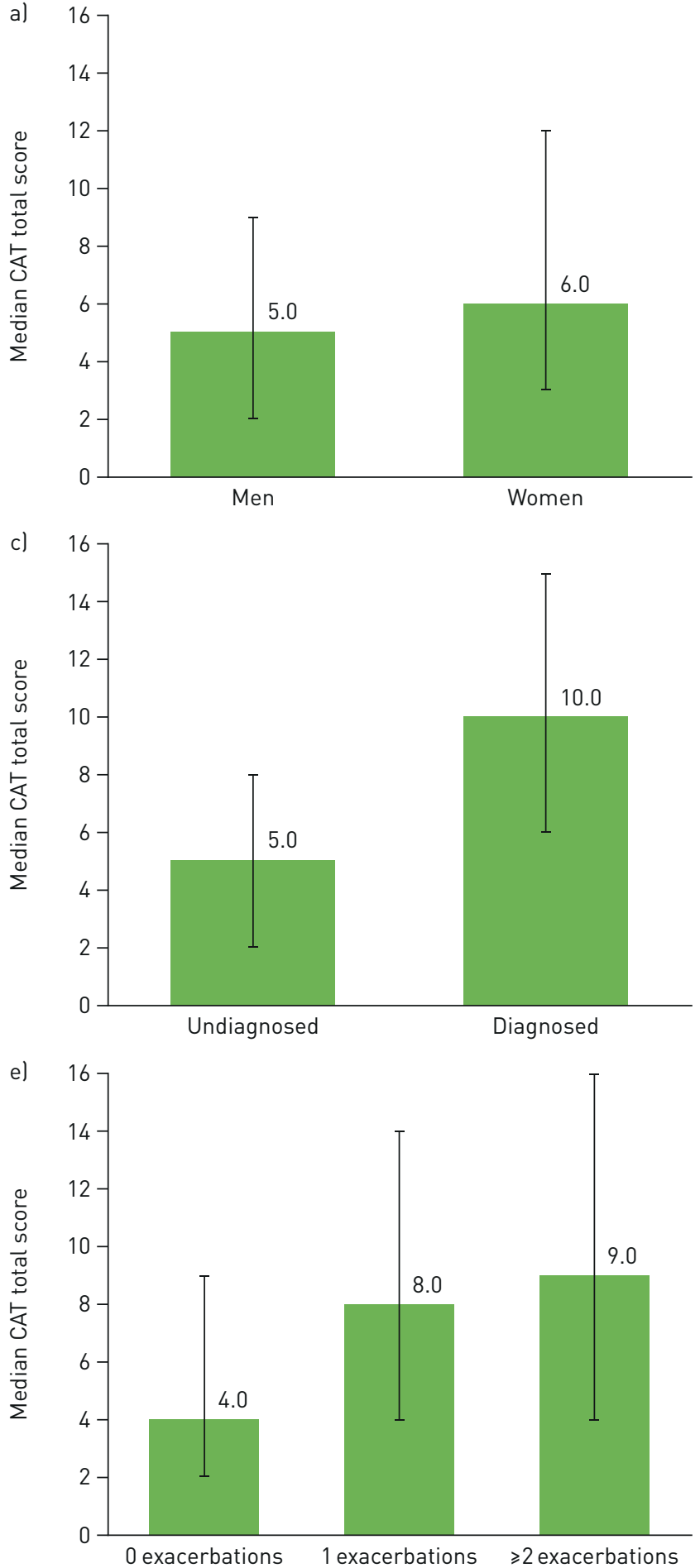
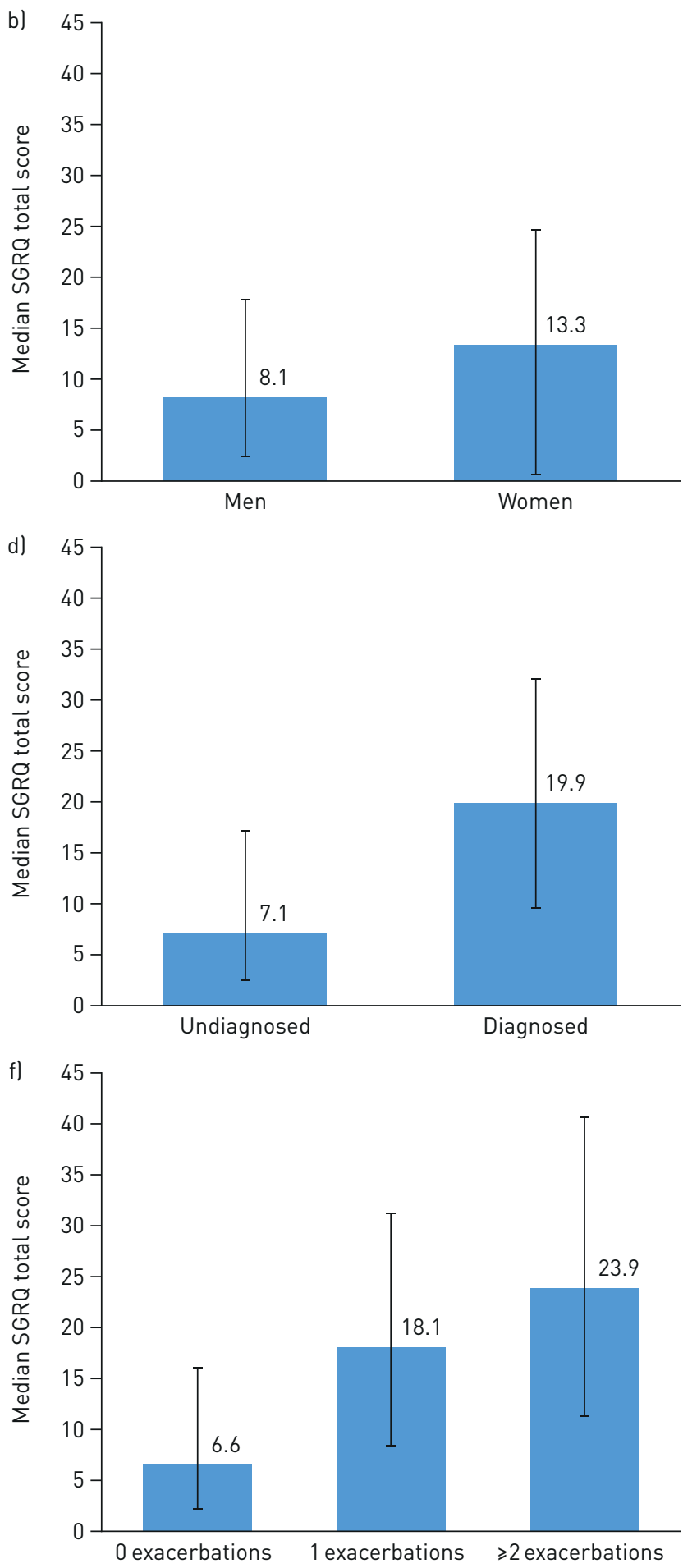

FIGURE 6 Health-related quality of life severity for people with COPD by: a) and b) sex, c) and d) the presence of a physician diagnosis of COPD, and e) and f) exacerbation frequency. CAT and SGRQ were measured at baseline for comparisons by sex and physician diagnosis of COPD, and at Visit 3 for comparisons by exacerbation history. Error bars represent interquartile range. $\mathrm{p}$-values were obtained by t-test (normal distribution) or Mann-Whitney U-test (not normal distribution) for sex and physician diagnosis subgroups. ANOVA (normal distribution) or Kruskal-Wallis test (not normal distribution) were performed for exacerbation subgroups. Analysis of variance subgroup comparisons of median (interquartile range) differences by sex, presence of a physician diagnosis of COPD, and exacerbation frequency were all significant ( $p<0.05)$. CAT: COPD Assessment Test; COPD: chronic obstructive pulmonary disease; HRQoL: health-related quality of life; SGRQ: St George's Respiratory Questionnaire.

mild COPD to those without COPD, no statistically significant difference in HRQoL measures were found. It is possible that people with mild COPD may not recognise their dyspnoea but modify their levels of physical activity to avoid this distressing symptom, and consequently do not notice a change in their 
TABLE 2 Dyspnoea severity and health related quality of life by sex, COPD physician diagnosis status, and exacerbation frequency for people with mild (GOLD 1) or moderate (GOLD 2) COPD

\begin{tabular}{|c|c|c|c|c|c|c|c|}
\hline & Subjects $n$ & MRC & MRC 1 & MRC 2 & $M R C \geqslant 3$ & CAT total score & SGRQ total score \\
\hline Mild COPD (GOLD 1) & 397 & & & & & & \\
\hline Women & 138 & $1.6 \pm 0.6$ & 68 (49.3) & 62 (44.9) & $8(5.8)$ & $5.0(3.0-9.0)$ & $8.0(2.7-17.1)$ \\
\hline p-value & & $<0.001$ & $<0.001$ & $<0.001$ & 0.073 & 0.049 & 0.039 \\
\hline Moderate COPD (GOLD 2) & 262 & & & & & & \\
\hline $\mathrm{p}$-value & & 0.026 & 0.029 & 0.137 & 0.304 & 0.028 & 0.023 \\
\hline \multicolumn{8}{|c|}{ Dyspnoea and HRQoL by COPD diagnosis } \\
\hline Mild COPD (GOLD 1) & 397 & & & & & & \\
\hline Diagnosed COPD & 66 & $1.6 \pm 0.6$ & $28(42.4)$ & $35(53.0)$ & $3(4.5)$ & $7.0(5.0-12.0)$ & $13.9(7.1-20.0)$ \\
\hline Undiagnosed COPD & 331 & $1.3 \pm 0.6$ & $230(69.5)$ & 90 (27.2) & $11(3.3)$ & $4.0(2.0-7.0)$ & $6.2(2.0-12.4)$ \\
\hline p-value & & $<0.001$ & $<0.001$ & $<0.001$ & 0.712 & $<0.001$ & $<0.001$ \\
\hline \multicolumn{8}{|c|}{ Dyspnoea and $H R Q \circ L$ by exacerbation frequency $\#$} \\
\hline Mild COPD (GOLD 1) & 282 & & & & & & \\
\hline 0 & 227 & $1.3 \pm 0.5$ & $163(71.8)$ & $59(26.0)$ & $5(2.2)$ & $4.0(2.0-7.0)$ & $5.1(1.6-12.3)$ \\
\hline 1 & 39 & $1.6 \pm 0.8$ & $23(59.0)$ & $9(23.1)$ & $7(17.9)$ & $7.0(3.0-11.0)$ & $12.6(6.8-21.5)$ \\
\hline$\geqslant 2$ & 16 & $1.8 \pm 0.7$ & $6(37.5)$ & $8(50.0)$ & 2 (12.5) & $8.5(3.5-15.0)$ & $20.7(8.4-35.6)$ \\
\hline Overall p-value & & 0.002 & 0.007 & 0.094 & $<0.001$ & $<0.001$ & $<0.001$ \\
\hline Moderate COPD (GOLD 2) & 185 & & & & & & \\
\hline 0 & 128 & $1.5 \pm 0.6$ & $75(58.6)$ & $44(34.4)$ & $9(7.0)$ & $6.5(3.0-11.0)$ & $11.5(3.6-24.3)$ \\
\hline 1 & 35 & $1.9 \pm 0.8$ & $13(37.1)$ & 15 (42.9) & $7(20.0)$ & $11.0(6.0-17.0)$ & $24.0(15.3-35.4)$ \\
\hline$\geqslant 2$ & 22 & $1.8 \pm 0.7$ & $8(36.4)$ & $11(50.0)$ & $3(13.6)$ & $9.5(5.0-18.0)$ & $32.5(12.5-42.8)$ \\
\hline Overall p-value & & $<0.011$ & 0.024 & 0.300 & 0.066 & 0.002 & $<0.001$ \\
\hline
\end{tabular}

Data are presented as $\mathrm{n}$, mean $\pm \mathrm{SD}$, median (interquartile range) or $\mathrm{n}(\%)$, unless otherwise stated. CAT: COPD Assessment Test; COPD: chronic obstructive pulmonary disease; GOLD: Global Initiative for Chronic Obstructive Lung Disease; HRQoL: health-related quality of life; MRC: Medical Research Council; SGRQ: St George's Respiratory Questionnaire. MRC was measured at baseline for comparisons by sex and physician diagnosis of COPD, and at Visit 3 for comparisons by exacerbation history. \#: Number of exacerbations in the 12 months preceding Visit 3. p-values were obtained by performing Chi-squared or Fisher's exact test for category variables, and t-test (normal distribution) or Mann Whitney U test (not normal distribution) for continuous variables. Bold indicates statistical significance.

HRQoL [30, 31]. Indeed, people with mild-moderate COPD have reported abnormally low daily step rates and physical activity compared with healthy controls [32]. The results of our study suggest that dyspnoea is a feature of people with mild-COPD even in a population-based cohort, and that they can be identified provided they are carefully questioned about their level of dyspnoea using the MRC scale. Failure to identify dyspnoea in people with undiagnosed mild COPD may contribute to delayed diagnosis and treatment initiation. To overcome this, there is a need to implement standardised methods to measure exertional dyspnoea in people at risk of COPD [30, 31].

We also demonstrated that women with mild COPD reported greater dyspnoea and worse HRQoL. This is consistent with previous population-based studies which found that women had more severe dyspnoea and exacerbations than men, despite similar airflow limitation [16, 33]. These discrepancies may be attributed to societal and/or biological factors [34]. For example, women with COPD are more likely to utilise healthcare resources [14]. Women tend to have smaller lungs, narrower airways [17, 34, 35], greater airway hyperresponsiveness [16] and exhibit different smoking patterns and metabolism of cigarette-smoke $[16,17,34]$. One study demonstrated that dyspnoea was higher for a given ventilation and power output during exercise testing in women than men with mild COPD [36]. However, the differences were no longer seen when power output was adjusted for body mass and ventilation was adjusted for maximum voluntary ventilation, indicating that differences in body size and lung volume contribute importantly to the sex disparity in dyspnoea [36]. Indeed, Екsтrом and colleagues [37, 38] demonstrated that higher prevalence and severity of dyspnoea among women in the general-population is related to smaller absolute lung volumes. Therefore, mild COPD may have greater symptomatic consequences in women because of biologically lower maximal ventilatory capacity. 
People with COPD who had experienced exacerbations during the previous year reported more dyspnoea and worse HRQoL than those who did not. Our study found that $19.5 \%$ of people with mild COPD experienced exacerbations, in keeping with the "exacerbation-susceptible" phenotype identified within the ECLIPSE (Evaluation of COPD Longitudinally to Identify Predictive Surrogate End-points) study [39]. Additionally, given that MRC dyspnoea score correlates with exacerbation frequency [39], these findings may indicate that identifying dyspnoeic individuals with mild COPD could allow for the recognition of the "exacerbation-susceptibility" phenotype earlier in the course of COPD and for earlier interventions to reduce exacerbations, healthcare utilisation, and, potentially, alter disease progression. Our findings need not imply a causal relationship. Exacerbations are patient-defined events, and it is plausible that individuals with heightened perception of somatic sensations, particularly respiratory sensations, experience more exacerbations

The major strength of our study is that participants were randomly sampled from a non-clinical population. This provides a unique insight early in the COPD disease course, even prior to diagnosis. This is the only study to directly compare dyspnoea and HRQoL among people with mild COPD with those without COPD, identifying significant symptom burden in mild COPD. In addition, as this study included people with mild COPD, these results may be more relevant to primary care practices than previous studies [1, 10, 29]. TAN et al. [9] estimated that $16.7 \%$ of Canadian adults aged $\geqslant 40$ years had COPD (defined as $\mathrm{FEV}_{1} / \mathrm{FVC}<0.7$ ) according to post-bronchodilator spirometry, with approximately $53 \%$ of these people being classified to have mild (GOLD1) COPD. Another advantage of CanCOLD is that it used the same sampling methodology for prevalence assessment as the multinational Burden of Obstructive Lung Disease study, which was conducted across 12 sites worldwide [40], thereby allowing cautious extrapolation of our findings to other countries.

This study has its limitations. Dyspnoea is a complex symptom that manifests in three domains: symptom impact, sensory perception and affective distress [41]. In our study, only symptom impact was measured. Nonetheless, these domains are intrinsically linked, with dyspnoea symptoms able to induce secondary responses in sensory and affective dimensions [42]. In people with chronic dyspnoea, higher perceived severity of breathlessness and its unpleasantness is associated with worse perceived HRQoL [43]. Although our findings demonstrated that people with mild COPD are more dyspnoeic than those without COPD, particularly never-smokers, this was based on MRC2 versus 1 only and was not maintained for MRC $\geqslant 3$ versus 1 . This reflects the fact that only a few people with mild COPD or without COPD reported $M R C \geqslant 3$. Therefore, meaningful conclusions cannot be drawn when comparing $M R C \geqslant 3$ versus 1 for these subgroups. Also, by using a fixed post-bronchodilator $\mathrm{FEV}_{1} / \mathrm{FVC}$ ratio of $<0.7$ to diagnose COPD, instead of the lower limit of normal $\mathrm{FEV}_{1} / \mathrm{FVC}$ [44], there could have been some overdiagnosis of COPD in older people; however, a recent study by ВНАтт et al. [45] supports use of the fixed threshold to identify individuals at risk of clinically significant COPD. The pathophysiological mechanisms underlying the observed differences in the prevalence and severity of dyspnoea in people with compared to without mild COPD were not explored in this study. However, based on physiological studies in symptomatic adults with diagnosed mild COPD recruited from clinical settings [46, 47], it is reasonable to hypothesise that these observed between-group differences reflect abnormalities in pulmonary microvasculature, small airways, pulmonary gas exchange and/or lung volume dynamics in people with mild COPD. We also cannot exclude the possibility that reports of greater dyspnoea are the consequence of diagnostic labelling. Additionally, given the large Caucasian representation in CanCOLD, our results may not be generalisable to non-Caucasian populations.

In conclusion, our findings provide new, important information that aid healthcare professionals who see people at risk of developing COPD and people with mild COPD. Specifically, our findings highlight the importance of carefully questioning people at risk of COPD about dyspnoea or any impairment of HRQoL for earlier identification of individuals with mild COPD. Nonetheless, questions remain regarding exertional dyspnoea in mild COPD, and more sensitive, comprehensive means to assess people with mild COPD with clinically significant symptoms are required. Furthermore, our study highlights the need to develop a more detailed understanding of the mechanisms of dyspnoea in women and among people who exacerbate frequently in order to facilitate more targeted identification, diagnosis, and treatment initiation.

Acknowledgments: The authors thank the men and women who participated in the study and the many members of the CanCOLD collaborative research group.

Executive Committee: Jean Bourbeau (McGill University, Montreal, QC, Canada); Wan C. Tan, J. Mark FitzGerald, Don D. Sin (University of British Columbia, Vancouver, BC, Canada); Darcy D. Marciniuk (University of Saskatoon, Saskatoon, SK, Canada); Denis E. O’Donnell (Queen's University, Kingston, ON, Canada); Paul Hernandez (Dalhousie University, Halifax, NS, Canada); Kenneth R. Chapman (University of Toronto, Toronto, ON, Canada); Brandie Walker (University of Calgary, Calgary, AB, Canada); Shawn Aaron (University of Ottawa, Ottawa, ON, Canada); François Maltais (University of Laval, Quebec City, QC, Canada). International Advisory Board: Jonathon Samet (the Keck 
School of Medicine of USC, Los Angeles, CA, USA); Milo Puhan (John Hopkins School of Public Health, Baltimore, MD, USA); Qutayba Hamid (McGill University, Montreal, QC, Canada); James C. Hogg (University of British Columbia, Vancouver, BC, Canada). Operations Center: Jean Bourbeau (Principal Investigator), Dany Doiron, Palmina Mancino, Pei Zhi Li, Dennis Jensen, Carolyn Baglole (McGill University, Montreal, QC, Canada); Yvan Fortier (Laboratoire telematique, Quebec Respiratory Health Network, Fonds de la recherche en santé du Québec (FRQS)); Wan C. Tan (co-Principal Investigator), Don D. Sin, Julia Yang, Jeremy Road, Joe Comeau, Adrian Png, Kyle Johnson, Harvey Coxson, Jonathon Leipsic, Cameron Hague (University of British Columbia, Vancouver, BC, Canada), Miranda Kirby (Ryerson University, Toronto, ON, Canada) Economic Core: Mohsen Sadatsafavi (University of British Columbia, Vancouver, BC, Canada). Public Health Core: Teresa To, Andrea Gershon (University of Toronto, Toronto, ON Canada). Data Management and Quality Control: Wan C. Tan, Harvey Coxson (University of British Columbia, Vancouver, BC, Canada); Jean Bourbeau, Pei-Zhi Li, Zhi Song, Andrea Benedetti, Dennis Jensen (McGill University, Montreal, QC, Canada); Yvan Fortier (Laboratoire telematique, Quebec Respiratory Health Network, FRQS); Miranda Kirby (Ryerson University, Toronto, ON, Canada). Field Centres: Wan C. Tan (Principal Investigator), Christine Lo, Sarah Cheng, Elena Un, Cynthia Fung, Wen Tiang Wang, Liyun Zheng, Faize Faroon, Olga Radivojevic, Sally Chung, Carl Zou (University of British Columbia, Vancouver, BC, Canada); Jean Bourbeau (Principal Investigator), Palmina Mancino, Jacinthe Baril, Laura Labonte (McGill University, Montreal, QC, Canada); Kenneth Chapman (Principal Investigator), Patricia McClean, Nadeen Audisho (University of Toronto, Toronto, ON, Canada); Brandie Walker (Principal Investigator), Curtis Dumonceaux, Lisette Machado (University of Calgary, Calgary, AB, Canada); Paul Hernandez (Principal Investigator), Scott Fulton, Kristen Osterling, Denise Wigerius (University of Halifax, Halifax, NS, Canada); Shawn Aaron (Principal Investigator), Kathy Vandemheen, Gay Pratt, Amanda Bergeron (University of Ottawa, Ottawa, ON, Canada); Denis O’Donnell (Principal Investigator), Matthew McNeil, Kate Whelan (Queen's University, Kingston, ON, Canada); François Maltais (Principal Investigator), Cynthia Brouillard (University of Laval, Quebec City, QC, Canada); Darcy Marciniuk (Principal Investigator), Ron Clemens, Janet Baran, Candice Leuschen (University of Saskatoon, Saskatoon, SK, Canada).

Conflict of interest: M. Cherian reports the study is currently funded by the Canadian Respiratory Research Network, the Canadian Institutes of Health Research, AstraZeneca Canada Ltd, Boehringer Ingelheim Canada Ltd, GlaxoSmithKline Canada Ltd and Novartis. Previous study funding partners were the Respiratory Health Network of the Fonds de la recherche en santé du Québec, the Foundation of the McGill University Health Centre, Almirall, Merck, Nycomed, Pfizer Canada Ltd and Theratechnologies. Medical writing support provided by Fishawack Communications Ltd was funded by GSK. D. Jensen reports the study is currently funded by the Canadian Respiratory Research Network, the Canadian Institutes of Health Research, AstraZeneca Canada Ltd, Boehringer Ingelheim Canada Ltd, GlaxoSmithKline Canada Ltd and Novartis. Previous study funding partners were the Respiratory Health Network of the Fonds de la recherche en santé du Québec, the Foundation of the McGill University Health Centre, Almirall, Merck, Nycomed, Pfizer Canada Ltd and Theratechnologies. Medical writing support provided by Fishawack Communications Ltd was funded by GSK. He also reports grants and personal fees from AstraZeneca, and grants from Boehringer Ingelheim, Novartis and Tilray, outside the submitted work. W.C. Tan reports the study is currently funded by the Canadian Respiratory Research Network, the Canadian Institutes of Health Research, AstraZeneca Canada Ltd, Boehringer Ingelheim Canada Ltd, GlaxoSmithKline Canada Ltd and Novartis. Previous study funding partners were the Respiratory Health Network of the Fonds de la recherche en santé du Québec, the Foundation of the McGill University Health Centre, Almirall, Merck, Nycomed, Pfizer Canada Ltd and Theratechnologies. Medical writing support provided by Fishawack Communications Ltd was funded by GSK. S. Mursleen reports the study is currently funded by the Canadian Respiratory Research Network, the Canadian Institutes of Health Research, AstraZeneca Canada Ltd, Boehringer Ingelheim Canada Ltd, GlaxoSmithKline Canada Ltd and Novartis. Previous study funding partners were the Respiratory Health Network of the Fonds de la recherche en santé du Québec, the Foundation of the McGill University Health Centre, Almirall, Merck, Nycomed, Pfizer Canada Ltd and Theratechnologies. Medical writing support provided by Fishawack Communications Ltd was funded by GSK. S. Mursleen is an employee of and holds shares/options in GSK. E.C. Goodall reports the study is currently funded by the Canadian Respiratory Research Network, the Canadian Institutes of Health Research, AstraZeneca Canada Ltd, Boehringer Ingelheim Canada Ltd, GlaxoSmithKline Canada Ltd and Novartis. Previous study funding partners were the Respiratory Health Network of the Fonds de la recherche en santé du Québec, the Foundation of the McGill University Health Centre, Almirall, Merck, Nycomed, Pfizer Canada Ltd and Theratechnologies. Medical writing support provided by Fishawack Communications Ltd was funded by GSK. E.C. Goodall is an employee of GSK. G.A. Nadeau reports the study is currently funded by the Canadian Respiratory Research Network, the Canadian Institutes of Health Research, AstraZeneca Canada Ltd, Boehringer Ingelheim Canada Ltd, GlaxoSmithKline Canada Ltd and Novartis. Previous study funding partners were the Respiratory Health Network of the Fonds de la recherche en santé du Québec, the Foundation of the McGill University Health Centre, Almirall, Merck, Nycomed, Pfizer Canada Ltd and Theratechnologies. Medical writing support provided by Fishawack Communications Ltd was funded by GSK. G.A. Nadeau was an employee of and held shares/options in GSK at the time of the analysis. A.M. Awan reports the study is currently funded by the Canadian Respiratory Research Network, the Canadian Institutes of Health Research, AstraZeneca Canada Ltd, Boehringer Ingelheim Canada Ltd, GlaxoSmithKline Canada Ltd and Novartis. Previous study funding partners were the Respiratory Health Network of the Fonds de la recherche en santé du Québec, the Foundation of the McGill University Health Centre, Almirall, Merck, Nycomed, Pfizer Canada Ltd and Theratechnologies. Medical writing support provided by Fishawack Communications Ltd was funded by GSK. A.M. Awan is an employee of GlaxoSmithKline. D.D. Marciniuk reports the study is currently funded by the Canadian Respiratory Research Network, the Canadian Institutes of Health Research, AstraZeneca Canada Ltd, Boehringer Ingelheim Canada Ltd, GlaxoSmithKline Canada Ltd and Novartis. Previous study funding partners were the Respiratory Health Network of the Fonds de la recherche en santé du Québec, the Foundation of the McGill University Health Centre, Almirall, Merck, Nycomed, Pfizer Canada Ltd and Theratechnologies. Medical writing support provided by Fishawack Communications Ltd was funded by GSK. He also reports consultancy fees and research funding (managed by University of Saskatchewan) from AstraZeneca and Boehringer Ingelheim; consultancy fees from the Canadian Foundation for Healthcare Improvement, and the Chinese Committee of Health and Family Planning; consultancy fees and research funding (managed by University of Saskatchewan) from GSK; consultancy fees from Health Canada; consultancy fees and research funding (managed by University of Saskatchewan) from the Lung Association of Saskatchewan; consultancy fees from Mylan; consultancy fees 
and research funding (managed by University of Saskatchewan) from Novartis; consultancy fees from the Saskatchewan Ministry of Health, Saskatchewan Health Authority, and Yukon Health and Social Services; research funding (managed by University of Saskatchewan) from Canada Health Infoway, the Canadian Institute of Health Research, the Lung Health Institute of Canada, Sanofi, the Saskatchewan Health Research Foundation and Schering-Plough; and is a spokesperson on behalf of the Canadian Thoracic Society, outside the submitted work. B.L. Walker reports the study is currently funded by the Canadian Respiratory Research Network, the Canadian Institutes of Health Research, AstraZeneca Canada Ltd, Boehringer Ingelheim Canada Ltd, GlaxoSmithKline Canada Ltd and Novartis. Previous study funding partners were the Respiratory Health Network of the Fonds de la recherche en santé du Québec, the Foundation of the McGill University Health Centre, Almirall, Merck, Nycomed, Pfizer Canada Ltd and Theratechnologies. Medical writing support provided by Fishawack Communications Ltd was funded by GSK. She also reports advisory board and speaker fees from AstraZeneca and GSK, outside the submitted work. S.D. Aaron reports the study is currently funded by the Canadian Respiratory Research Network, the Canadian Institutes of Health Research, AstraZeneca Canada Ltd, Boehringer Ingelheim Canada Ltd, GlaxoSmithKline Canada Ltd and Novartis. Previous study funding partners were the Respiratory Health Network of the Fonds de la recherche en santé du Québec, the Foundation of the McGill University Health Centre, Almirall, Merck, Nycomed, Pfizer Canada Ltd, and Theratechnologies. Medical writing support provided by Fishawack Communications Ltd was funded by GSK D.E. O'Donnell reports the study is currently funded by the Canadian Respiratory Research Network, the Canadian Institutes of Health Research, AstraZeneca Canada Ltd, Boehringer Ingelheim Canada Ltd, GlaxoSmithKline Canada Ltd and Novartis. Previous study funding partners were the Respiratory Health Network of the Fonds de la recherche en santé du Québec, the Foundation of the McGill University Health Centre, Almirall, Merck, Nycomed, Pfizer Canada Ltd, and Theratechnologies. Medical writing support provided by Fishawack Communications Ltd was funded by GSK. K.R. Chapman reports the study is currently funded by the Canadian Respiratory Research Network, the Canadian Institutes of Health Research, AstraZeneca Canada Ltd, Boehringer Ingelheim Canada Ltd, GlaxoSmithKline Canada Ltd and Novartis. Previous study funding partners were the Respiratory Health Network of the Fonds de la recherche en santé du Québec, the Foundation of the McGill University Health Centre, Almirall, Merck, Nycomed, Pfizer Canada Ltd, and Theratechnologies. Medical writing support provided by Fishawack Communications Ltd. was funded by GSK. He also reports grants from Bayer, grants and personal fees from CSL Behring, grants from Grifols, grants and personal fees from Takeda, grants from Vertex, grants and personal fees from Mereo Biopharma, and grants and personal fees from Sanofi, during the conduct of the study. F. Maltais reports the study is currently funded by the Canadian Respiratory Research Network, the Canadian Institutes of Health Research, AstraZeneca Canada Ltd, Boehringer Ingelheim Canada Ltd, GlaxoSmithKline Canada Ltd and Novartis. Previous study funding partners were the Respiratory Health Network of the Fonds de la recherche en santé du Québec, the Foundation of the McGill University Health Centre, Almirall, Merck, Nycomed, Pfizer Canada Ltd, and Theratechnologies. Medical writing support provided by Fishawack Communications Ltd. was funded by GSK. He also reports research grants paid to his institution from AstraZeneca, GSK and Sanofi, a research grant and fees for speaker bureaus/consultancy from Novartis, grants and personal fees from Boehringer Ingelheim, and a research grant paid to his institution and fees for speaker bureaus/ consultancy from Grifols, outside the submitted work. P. Hernandez reports the study is currently funded by the Canadian Respiratory Research Network, the Canadian Institutes of Health Research, AstraZeneca Canada Ltd, Boehringer Ingelheim Canada Ltd, GlaxoSmithKline Canada Ltd and Novartis. Previous study funding partners were the Respiratory Health Network of the Fonds de la recherche en santé du Québec, the Foundation of the McGill University Health Centre, Almirall, Merck, Nycomed, Pfizer Canada Ltd, and Theratechnologies. Medical writing support provided by Fishawack Communications Ltd. was funded by GSK. He also reports honoraria for a medical advisory board from Actelion; honoraria for a medical advisory board and speaker fees for continuing health education, and funding to his institution for conduct of clinical trials from AstraZeneca and Boehringer Ingelheim; funding to his institution for conduct of clinical trials from Cyclomedica; honoraria for medical advisory boards from GlaxoSmithKline and Novartis; funding to his institution for conduct of clinical trials Respivant and Grifols; honoraria for medical advisory boards from Sanofi and Teva; and funding to his institution for conduct of clinical trials from Vertex, all outside the submitted work. D.D. Sin reports the study is currently funded by the Canadian Respiratory Research Network, the Canadian Institutes of Health Research, AstraZeneca Canada Ltd, Boehringer Ingelheim Canada Ltd, GlaxoSmithKline Canada Ltd and Novartis. Previous study funding partners were the Respiratory Health Network of the Fonds de la recherche en santé du Québec, the Foundation of the McGill University Health Centre, Almirall, Merck, Nycomed, Pfizer Canada Ltd, and Theratechnologies. Medical writing support provided by Fishawack Communications Ltd. was funded by GSK. He also reports an honorarium for speaking engagement from AstraZeneca and one for attending an advisory board from Boehringer Ingelheim, outside the submitted work. A. Benedetti reports the study is currently funded by the Canadian Respiratory Research Network, the Canadian Institutes of Health Research, AstraZeneca Canada Ltd, Boehringer Ingelheim Canada Ltd, GlaxoSmithKline Canada Ltd and Novartis; grants, and lecture and advisory board fees from AstraZeneca Canada Ltd, Boehringer Ingelheim Canada Ltd and GlaxoSmithKline Canada Ltd; grants from Canadian Institutes of Health Research and the Respiratory Health Network of the Fonds de la recherche en santé du Québec; medical writing support provided by Fishawack Communications Ltd funded by GSK; grants from Novartis; and grants from Almirall, Merck, Nycomed, Pfizer Canada Ltd, Theratechnologies and The Foundation of the McGill University Health Centre, all during the conduct of the study. J. Bourbeau reports the study is currently funded by the Canadian Respiratory Research Network, the Canadian Institutes of Health Research, AstraZeneca Canada Ltd, Boehringer Ingelheim Canada Ltd, GlaxoSmithKline Canada Ltd and Novartis; grants, and lecture and advisory board fees from AstraZeneca Canada Ltd, Boehringer Ingelheim Canada Ltd and GlaxoSmithKline Canada Ltd; grants from Canadian Institutes of Health Research and the Respiratory Health Network of the Fonds de la recherche en santé du Québec; medical writing support provided by Fishawack Communications Ltd funded by GSK; grants from Novartis; and grants from Almirall, Merck, Nycomed, Pfizer Canada Ltd, Theratechnologies and The Foundation of the McGill University Health Centre, all during the conduct of the study; and consultancy and lecture fees from the Canadian Thoracic Society and CHEST; grants from the Foundation of the MUHC and Aerocrine; grants, and lecture and advisory board fees from Grifols, Novartis and Trudell, and grants from Canadian Institutes of Health Research, all outside the submitted work.

Support statement: This analysis was funding by GlaxoSmithKline (GSK Study HO-15-15913). The Canadian Cohort Obstructive Lung Disease (CanCOLD; NCT00920348) study is currently funded by the Canadian Respiratory Research 
Network, the Canadian Institutes of Health Research (CIHR; CIHR/Rx\&D Collaborative Research Program Operating Grants- 93326), and the following industry partners: AstraZeneca Canada Ltd; Boehringer Ingelheim Canada Ltd, GlaxoSmithKline (GSK) Canada Ltd; and Novartis. Investigators at Research Institute of the McGill University Health Centre Montreal and iCAPTURE Centre Vancouver led the project. Previous funding partners were the Respiratory Health Network of the Fonds de la recherche en santé du Québec (FRQS), the Foundation of the McGill University Health Centre, and industry partners: Almirall; Merck, Nycomed; Pfizer Canada Ltd; and Theratechnologies. With the exception of the GSK authors (please see author contributions), the funders had no role in the study design, data collection, and analysis, or preparation of the manuscript. Funding information for this article has been deposited with the Crossref Funder Registry.

\section{References}

1 Mullerova H, Lu C, Li H, et al. Prevalence and burden of breathlessness in patients with chronic obstructive pulmonary disease managed in primary care. PLoS One 2014; 9: e85540.

2 Kessler R, Partridge MR, Miravitlles M, et al. Symptom variability in patients with severe COPD: a pan-European cross-sectional study. Eur Respir J 2011; 37: 264-272.

3 Kaplan A, Thomas M. Screening for COPD: the gap between logic and evidence. Eur Respir Rev 2017; $26: 160113$.

4 Diab N, Gershon AS, Sin DD, et al. Underdiagnosis and overdiagnosis of chronic obstructive pulmonary disease. Am J Respir Crit Care Med 2018; 198: 1130-1139.

5 Price D, Freeman D, Cleland J, et al. Earlier diagnosis and earlier treatment of COPD in primary care. Prim Care Respir J 2011; 20: 15-22.

6 Han MK, Martinez CH, Au DH, et al. Meeting the challenge of COPD care delivery in the USA: a multiprovider perspective. Lancet Respir Med 2016; 4: 473-526.

7 Global Initiative for Chronic Obstructive Lung Disease. Global strategy for the diagnosis, management, and prevention of Chronic Obstructive Pulmonary Disease. 2020. https:/goldcopd.org/wp-content/uploads/2019/12/ GOLD-2020-FINAL-ver1.2-03Dec19_WMV.pdf Date last updated: 2020.

8 Raluy-Callado M, Lambrelli D, MacLachlan S, et al. Epidemiology, severity, and treatment of chronic obstructive pulmonary disease in the United Kingdom by GOLD 2013. Int J Chron Obstruct Pulmon Dis 2015; 10: 925-937.

9 Tan WC, Bourbeau J, FitzGerald JM, et al. Can age and sex explain the variation in COPD rates across large urban cities? A population study in Canada. Int J Tuberc Lung Dis 2011; 15: 1691-1698.

10 Dransfield MT, Bailey W, Crater G, et al. Disease severity and symptoms among patients receiving monotherapy for COPD. Prim Care Respir J 2011; 20: 46-53.

11 Rossi A, Butorac-Petanjek B, Chilosi M, et al. Chronic obstructive pulmonary disease with mild airflow limitation: current knowledge and proposal for future research - a consensus document from six scientific societies. Int J Chron Obstruct Pulmon Dis 2017; 12: 2593-2610.

12 Welte T, Vogelmeier C, Papi A. COPD: early diagnosis and treatment to slow disease progression. Int J Clin Pract 2015; 69: 336-349.

13 Zhang Y, Morgan RL, Alonso-Coello P, et al. A systematic review of how patients value COPD outcomes. Eur Respir J 2018; 52: 1800222.

14 Katsura H, Yamada K, Wakabayashi R, et al. Gender-associated differences in dyspnoea and health-related quality of life in patients with chronic obstructive pulmonary disease. Respirology 2007; 12: 427-432.

15 Kilic H, Kokturk N, Sari G, et al. Do females behave differently in COPD exacerbation? Int J Chron Obstruct Pulmon Dis 2015; 10: 823-830.

16 Jenkins CR, Chapman KR, Donohue JF, et al. Improving the management of COPD in women. Chest 2017; 151: 686-696.

17 Han MK, Arteaga-Solis E, Blenis J, et al. Female sex and gender in lung/sleep health and disease. increased understanding of basic biological, pathophysiological, and behavioral mechanisms leading to better health for female patients with lung disease. Am J Respir Crit Care Med 2018; 198: 850-858.

18 Labonte LE, Tan WC, Li PZ, et al. Undiagnosed chronic obstructive pulmonary disease contributes to the burden of health care use. Data from the CanCOLD study. Am J Respir Crit Care Med 2016; 194: 285-298.

19 Vestbo J, Anderson W, Coxson HO, et al. Evaluation of COPD Longitudinally to Identify Predictive Surrogate End-points (ECLIPSE). Eur Respir J 2008; 31: 869-873.

20 Tashkin DP, Celli B, Senn S, et al. A 4-year trial of tiotropium in chronic obstructive pulmonary disease. $N$ Engl J Med 2008; 359: 1543-1554.

21 Magnussen H, Disse B, Rodriguez-Roisin R, et al. Withdrawal of inhaled glucocorticoids and exacerbations of COPD. N Engl J Med 2014; 371: 1285-1294.

22 Bourbeau J, Tan WC, Benedetti A, et al. Canadian Cohort Obstructive Lung Disease (CanCOLD): Fulfilling the need for longitudinal observational studies in COPD. COPD 2014; 11: 125-132.

23 von Elm E, Altman DG, Egger M, et al. The Strengthening the Reporting of Observational Studies in Epidemiology (STROBE) Statement: Guidelines for reporting observational studies. Int J Surg 2014; 12 1495-1499.

24 Bestall JC, Paul EA, Garrod R, et al. Usefulness of the Medical Research Council (MRC) dyspnoea scale as a measure of disability in patients with chronic obstructive pulmonary disease. Thorax 1999; 54: 581.

25 Casanova C, Marin JM, Martinez-Gonzalez C, et al. Differential effect of modified Medical Research Council Dyspnea, COPD Assessment Test, and Clinical COPD Questionnaire for symptoms evaluation within the new GOLD staging and mortality in COPD. Chest 2015; 148: 159-168.

26 Bourbeau J, Bhutani M, Hernandez P, et al. CTS position statement: Pharmacotherapy in patients with COPDAn update. Can J Respir Crit Care Sleep Med 2017; 1: 222-241.

27 Gupta N, Pinto LM, Morogan A, et al. The COPD assessment test: a systematic review. Eur Respir J 2014; 44: 873-884.

28 Özgür ES, Özge C, Ilvan A, et al. Relationship between quality of life and multidimensional assessment indices in patients with COPD. Eur Respir J 2012; 40: Suppl 56, 727.

29 Agusti A, Calverley PMA, Celli B, et al. Characterisation of COPD heterogeneity in the ECLIPSE cohort. Respir Res 2010; 11: 122. 
Ekström M. Why treatment efficacy on breathlessness in laboratory but not daily life trials? The importance of standardized exertion. Curr Opin Support Palliat Care 2019; 13: 179-183.

31 Lewthwaite H, Koch EM, Tracey L, et al. Standardized measurement of breathlessness during exercise. Curr Opin Support Palliat Care 2019; 13: 152-160.

32 Troosters T, Sciurba F, Battaglia S, et al. Physical inactivity in patients with COPD, a controlled multi-center pilot-study. Respir Med 2010; 104: 1005-1011.

33 Celli B, Vestbo J, Jenkins CR, et al. Sex differences in mortality and clinical expressions of patients with chronic obstructive pulmonary disease. The TORCH experience. Am J Respir Crit Care Med 2011; 183: 317-322.

34 Barnes PJ. Sex differences in chronic obstructive pulmonary disease mechanisms. Am J Respir Crit Care Med 2016; 193: 813-814.

35 Sheel AW, Guenette JA. Mechanics of breathing during exercise in men and women: sex versus body size differences? Exerc Sport Sci Rev 2008; 36: 128-134.

36 Guenette JA, Jensen D, Webb KA, et al. Sex differences in exertional dyspnea in patients with mild COPD physiological mechanisms. Respir Physiol Neurobiol 2011; 177: 218-227.

37 Ekstrom M, Schioler L, Gronseth R, et al. Absolute values of lung function explain the sex difference in breathlessness in the general population. Eur Respir J 2017; 49: 1602047.

38 Ekstrom M, Sundh J, Schioler L, et al. Absolute lung size and the sex difference in breathlessness in the general population. PLoS One 2018; 13: e0190876.

39 Hurst JR, Vestbo J, Anzueto A, et al. Susceptibility to exacerbation in chronic obstructive pulmonary disease. $N$ Engl J Med 2010; 363: 1128-1138.

40 Townend J, Minelli C, Mortimer K, et al. The association between chronic airflow obstruction and poverty in 12 sites of the multinational BOLD study. Eur Respir J 2017; 49: 1601880.

41 Parshall MB, Schwartzstein RM, Adams L, et al. An official American Thoracic Society statement: update on the mechanisms, assessment, and management of dyspnea. Am J Respir Crit Care Med 2012; 185: 435-452.

42 O’Donnell CR, Schwartzstein RM, Lansing RW, et al. Dyspnea affective response: comparing COPD patients with healthy volunteers and laboratory model with activities of daily living. BMC Pulm Med 2013; 13: 27.

43 Ekstrom M, Williams M, Johnson MJ, et al. Agreement between breathlessness severity and unpleasantness in people with chronic breathlessness: a longitudinal clinical study. J Pain Symptom Manage 2019; 57: 715-723.

44 Pellegrino R, Viegi G, Brusasco V, et al. Interpretative strategies for lung function tests. Eur Respir J 2005; 26: 948-968.

45 Bhatt SP, Balte PP, Schwartz JE, et al. Discriminative accuracy of FEV1:FVC thresholds for COPD-related hospitalization and mortality. JAMA 2019; 321: 2438-2447.

46 Elbehairy AF, Ciavaglia CE, Webb KA, et al. Pulmonary gas exchange abnormalities in mild chronic obstructive pulmonary disease. implications for dyspnea and exercise intolerance. Am J Respir Crit Care Med 2015; 191: 1384-1394.

47 Guenette JA, Chin RC, Cheng S, et al. Mechanisms of exercise intolerance in global initiative for chronic obstructive lung disease grade 1 COPD. Eur Respir J 2014; 44: 1177-1187. 